\title{
Smart Poverty Alleviation Architecture Based on Geomatics Big Data
}

\author{
Shuai $\mathrm{Wu}^{1}$, Ruichao $\mathrm{Qu}^{1}$,Chanling Pan ${ }^{1, *}$, Ziyuan $\mathrm{Bao}^{1}$, Xiaojian Feng ${ }^{1}$ \\ ${ }^{1}$ Guangxi Institute of Surveying and Mapping of Remote Sensing Information, Nanning, China - taotieyiyi@qq.com
}

KEY WORDS: Geomatics big data; Smart poverty alleviation; Architecture; Poverty alleviation recommendation;Multi-dimensional correlation analysis

\begin{abstract}
:
With the rapid development of geomatics industry, it has accumulated a large amount of data such as digital city and national geoinformation survey, entered the geomatics big data era. At present, there are some researches on the collection and display of poverty alleviation based on geomatics . However, there are relatively few studies on smart poverty alleviation . Many problems need to be solved. It proposes a smart poverty alleviation architecture based on large geomatics data.It realizes the collection and monitor of smart poverty alleviation in administrative regions at all Levels, such as household, village, Township and county.It realizes the visualization of smart poverty alleviation with geomatics big data.It can poverty alleviation recommendation precisely.Aiming at this model,it proposes a precise poverty alleviation recommendation algorithm based on multi-dimensional correlation analysis . It uses Higher Order Singular Value Decomposition(HOSVD) algorithm to mine the relationship between geomatics and poverty alleviation, and recommends poverty alleviation policies. The research has certain practice and test. The architecture can effectively recommend poverty alleviation assistance policies, improve the efficiency of poverty alleviation archives collation, shorten the period of poverty alleviation archives collation, and improve the storage and access methods of poverty alleviation archives. It improves the efficiency of poverty alleviation collection, monitoring and assistance.
\end{abstract}

\section{INTRODUCTION}

Since the reform and opening, China has successfully embarked on a road of poverty alleviation and development with Chinese characteristics, which has enabled more than 800 million rural poor to successfully get rid of poverty and laid a solid foundation for building a well-off society in an all-round way. China is the world's most poverty-stricken country and the first country to complete the United Nations Millennium Development Goals. Now, when poverty alleviation work enters a new stage -targeted poverty alleviation, poverty alleviation should be accurate to people, prevent the average from covering most.It requires more attention to the protection of basic livelihood and the lives of low-income people.It ensures that every rural poor is truly out of poverty. With the advancement of targeted poverty alleviation, the number of poor people in China will be reduced by more than 68 million by 2018 , and the number of rural poor is greatly reduced. However, the remaining poor people are mostly deeply impoverished. They are dispersed located in poor mountainous areas and it is very difficult for them to get rid of poverty. Therefore, how to help the deeply impoverished poor to achieve targeted poverty alleviation, and eliminate the phenomenon of returning to poverty has become a realistic problem in targeted poverty alleviation research.

Big data has basic features such as Volume, Velocity, Variety, Value and Veracity.It meets the realistic needs of targeted poverty alleviation and becomes a feasible path to achieve accurate poverty alleviation goals (Zhen et al., 2015). Mo (2016) proposed the application of big data to optimize the dynamics of poverty alleviation supervision. Zhao (2017) analyzed the support mechanism of big data for targeted poverty alleviation , and the targeted poverty alleviation model based on big data thinking. GanSu built China's first targeted poverty alleviation big data management platform, using big data supervision to regulate the situation and result of assistance. GuiZhou built a "poverty alleviation cloud" based on big data and cloud computing. a The "poverty alleviation cloud" was based on GIS, used the mobile terminal as a carrier ,and built a mobile patrol inspection system for poverty alleviation work focusing on creating archives for poor households and project funds.

These studies is based on poverty alleviation big data and GIS, and has achieved good poverty alleviation effects, but mainly use poverty alleviation big data and geographic information to locate and monitor poverty alleviation. There is data isolation phenomenon, and the application of interdisciplinary research and integrated integrated data analysis is insufficient (Zhang et al., 2017).They are less concerned about mining geomatics big data, such as the geographical coordinates, geographical similarity, contracted land plots of poor households. With the rapid development of geomatics industry, it has accumulated a large amount of data such as digital city and national geoinformation survey, entered the geomatics big data era.We can integrate poverty alleviation data from the geographic data big data dimension to help the poor and poor people in povertystricken mountain areas to get rid of poverty.

Therefore, this study proposes a smart poverty alleviation architecture based on large geomatics data.It realizes the collection and monitor of smart poverty alleviation in administrative regions at all Levels, such as household, village, Township and county.It realizes the visualization of smart poverty alleviation with geomatics big data.It can poverty alleviation recommendation precisely.Aiming at this model,it proposes a precise poverty alleviation recommendation algorithm based on multi-dimensional correlation analysis . It uses HOSVD algorithm to mine the relationship between geomatics and poverty alleviation, and recommends poverty alleviation policies.

\section{ARCHITECTTURE}

This paper proposes a smart poverty alleviation architecture based on geomatics big data, including the basic layer, data resource layer, data model layer and application layer, which is illustrated in Figure 1.

\subsection{Basic layer}

The cloud platform is located at the architecture' s basic layer, adopts the infrastructure-as-a-service (IaaS) cloud computing service model.It acquires computing resources, storage resources,

* Corresponding author: Chanling Pan

This work was supported by the National Archives Bureau advance research program of Science and Technology, China( Grant 2019-X-10). 
and network resources through the cloud platform. It can dynamically expand and configure the cloud platform resources to support for the construction of this architecture .

The GIS platform constructs a geomatics big data environment, supports multi-terminal GIS including android, Browser and Desktop-client.It makes the poverty alleviation spatialize,makes full use of cloud platform resources, realizes efficient and spatialized processing of smart poverty alleviation data.

Cloud platform, GIS platform, database management system, security devices and so on provide hardware and software support for the architecture.

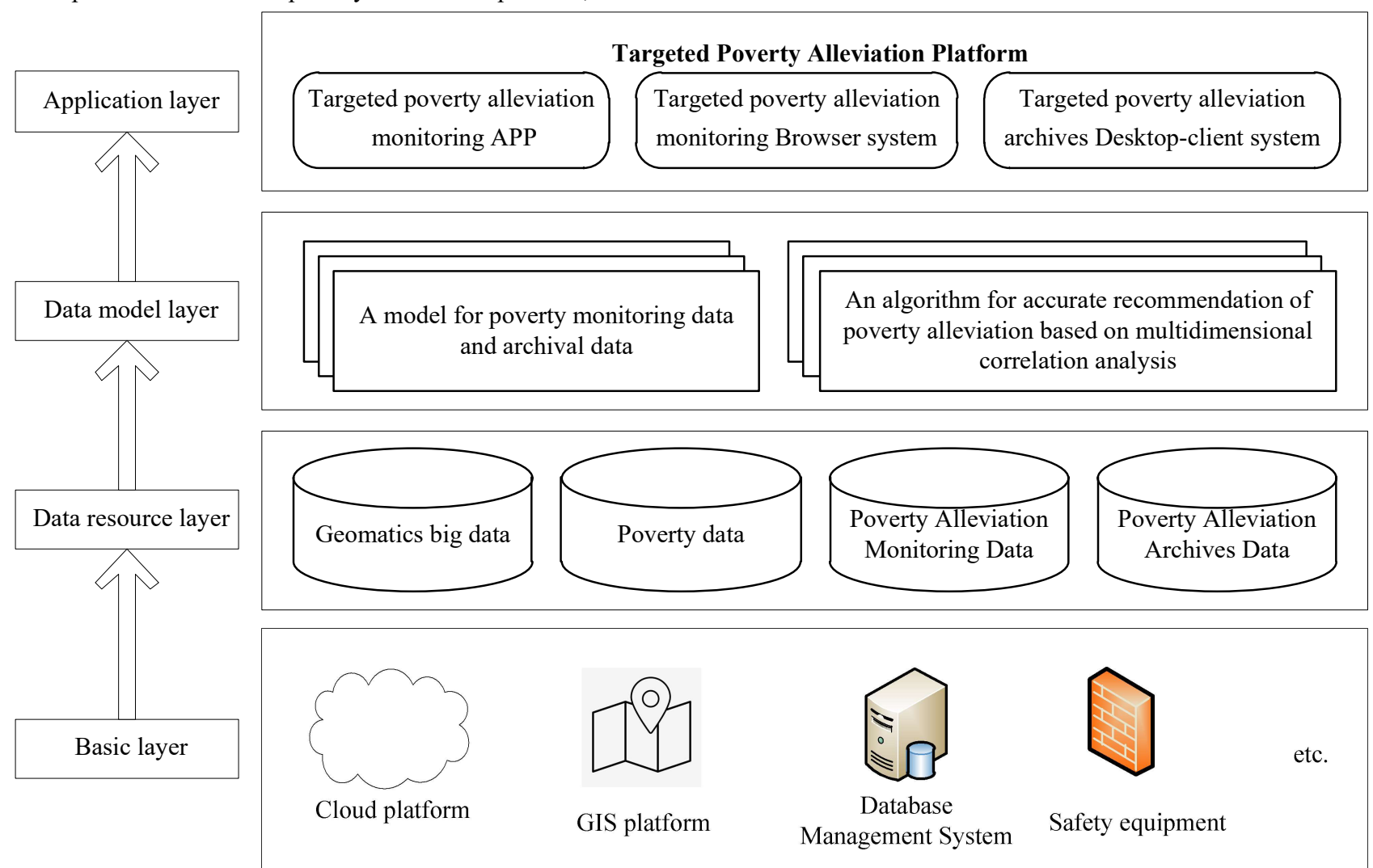

\subsection{Data resource layer}

This layer includes geomatics big data, poverty data, poverty alleviation monitoring data, poverty alleviation archives data. Geomatics big data includes the DLG, DOM, DEM, geographical name address points, administrative divisions and electronic map data from the digital geospatial data framework.It also includes the rural land contract management rights confirmation data, the third China national land survey . Poverty data includes the poor households' basic information, the family member information, and causes of poverty.

\begin{tabular}{|l|l|}
\hline Level & \multicolumn{1}{|c|}{ Poverty alleviation monitoring data } \\
\hline County & $\begin{array}{l}\text { Nine have vs one low: } \\
\text { have characteristic industry, house, basic } \\
\text { medical insurance, compulsory education, safe } \\
\text { drinking water, roads to villages,TV, basic } \\
\text { public services, social assistance, and low } \\
\text { incidence of rural poverty 3\%. } \\
\text { Eleven have vs one low: } \\
\text { have characteristic industry, house, basic } \\
\text { medical security, compulsory education, safe } \\
\text { drinking water, roads to villages, electricity, } \\
\text { basic public services, TV, village collectives } \\
\text { Economic income, a good "two committees" } \\
\text { team, and low incidence of rural poverty 3\%. } \\
\text { Elllage } \\
\text { Eleven have vs one low } \\
\text { Eight have vs one super: } \\
\text { have revenue stream, house, basic medical } \\
\text { security, compulsory education, roads to } \\
\text { villages,safe drinking water, electricity, TV, } \\
\text { and per capita net income of households in that } \\
\text { year more than 2,300 yuan }\end{array}$ \\
\hline
\end{tabular}

Table 1. Poverty alleviation monitoring data
The poverty alleviation monitoring data includes four levels of poverty alleviation monitoring data of county, township, village and household,as shown in Table 1.

The poverty alleviation archives data includes comprehensive archives, accurate identification archives, precise policy archives, and accurate poverty alleviation archives.

\subsection{Data model layer}

The main task of the data model layer is to model the poverty monitoring data and archive data in the data resource layer, then generate monitoring data and archive data to reduce the repeated collection work.In addition, it constructs a precise poverty alleviation recommendation algorithm based on multidimensional correlation analysis. The algorithm carries out multidimensional correlation analysis on geomatics, cadres, poor households, poverty reasons, poverty alleviation archives, poverty alleviation funds, poverty alleviation projects and so on. It uses HOSVD to mine the relationship between geomatics and poverty alleviation, and recommends poverty alleviation policies. By the data model layer, this paper constructs a multi-terminal collaboration mechanism based on geomatics big data, realizes data mining and reuse, and improves the efficiency of monitoring and helping recommendations.

\subsection{Application layer}

The targeted poverty alleviation platform is composed of the targeted poverty alleviation monitoring APP,the targeted poverty alleviation monitoring Browser system and the targeted poverty alleviation archives Desktop-client system.Multi terminals consisting of Android, Browser, and Desktop-client carry out collaborative monitoring, archiving, recommendation.It realizes the collection and monitoring of smart poverty alleviation data at county, township, village and household levels in the geomatics 
big data environment. It realizes the visualization of smart poverty alleviation, the smart poverty alleviation data mining, and the precise poverty alleviation recommendation.

\section{MULTI-TERMINAL COLLABORATION}

In the geomatics big data environment, APP is accurate to the household, monitors whether rural poor people are free from worries over food and clothing and have access to compulsory education, basic medical services and safe housing. The Browser system is accurate to the county,township, and village level, monitors whether poor villages and poor townships get out of poverty from the industry, roads,etc. The Desktop-client realizes the visual management, query and display of smart poverty alleviation based on geomatics big data , mines accurate poverty alleviation archives, provides accurate recommendations for poverty alleviation and pushes them to APP and Browser.

It models the poverty monitoring data and archive data in the data resource layer to generate monitoring data and archive data, and reduce the repeated collection work.

\subsection{Monitoring data}

The county is $\mathrm{C}$. C have $\mathrm{N}$ villages $\mathrm{Vi}\left(1<\mathrm{i}<\mathrm{N}, \mathrm{N} \in \mathrm{N}^{*}\right)$, and the village $\mathrm{Vi}$ has Mi poor households $\mathrm{Pi}, \mathrm{j}\left(1<\mathrm{j}<\mathrm{Mi}, \mathrm{Mi} \in \mathrm{N}^{*}\right)$.

Poverty alleviation monitoring data on the characteristic industries is $\mathrm{I}(\mathrm{x})$. Then the poverty alleviation monitoring data of the county $\mathrm{C}$ on the characteristic industries:

$$
\mathrm{I}(\mathrm{C})=\left[\frac{1}{\mathrm{~N}} \sum_{i=1}^{N} I(V i)\right]
$$

Poverty alleviation monitoring data on the housing security is $\mathrm{H}(\mathrm{x})$. Then the poverty alleviation monitoring data of the county $\mathrm{C}$ on the housing security:

$$
\mathrm{H}(\mathrm{C})=\left[\frac{1}{0.98 \times \sum_{i=1}^{N} M i} \sum_{i=1}^{N} \sum_{j=1}^{M i} H(P i, j)\right]
$$

\subsection{Archival Data}

Archives are classified into comprehensive categories, precise identification categories, precise implementation of policies and precise poverty alleviation categories. The precise poverty alleviation can be calculated by monitoring data.

The precise poverty eradication $T$ file of village $\mathrm{V}$ is $\mathrm{A}(\mathrm{T}, \mathrm{V})$ :

$$
\mathrm{A}(\mathrm{T}, \mathrm{V})=\sum_{i} J(V, Y i)
$$

Where $\mathrm{Yi}$ is year, $\mathrm{J}(\mathrm{V}, \mathrm{Yi})$ is the poverty eradication monitoring data of village $\mathrm{V}$ in year $\mathrm{Yi}$.

\section{RECOMMENDATION ALGORITHM}

Poverty alleviation is a major livelihood issue, covering government, transportation, education, bank, medical and other departments. How to mine valuable information from a wide range of multi-dimensional poverty alleviation data, provide accurate and rapid rich poverty alleviation recommendations for poor households is a realistic problem for poverty alleviation research. In order to achieve accurate poverty alleviation recommendation, the tensor HOSVD is used to analyze the multi-dimensional correlation of poverty alleviation data.

\subsection{Construct Subtensor}

It constructs three sub-tensor models of poverty-stricken households, assistance measures and poverty alleviation implementation scenarios to represent these multi-dimensional poverty alleviation data. Table 2 is the properties of these three tensor models .
The data of poor household tensor is from the poor households data and geomatics big data,the contracted plots data are extracted from the farmers' contracted plots data in the rural land contract management rights confirmation and the accessory vegetation data of land plot in the third China national land survey.The data of poverty alleviation measures tensor is from poverty alleviation archives data and poverty alleviation monitoring data. In the poverty alleviation situation tensor, the location is counties, townships, villages, homes and contracted plots.

\begin{tabular}{|c|c|}
\hline plots. & Dimension \\
\hline Tensor & Poverty reason \\
& Family situation \\
& Spatial Information of Poor Households \\
Spatial information of contracted plots \\
Poverty alleviation \\
measures & Education poverty alleviation \\
& Financial poverty alleviation \\
& Industrial poverty alleviation \\
& Poverty alleviation through relocation \\
Public service poverty alleviation \\
Poverty alleviation \\
situation & Time (year) \\
& Location \\
\hline
\end{tabular}

Table 2. Dimensions and ranges of tensors

4.2 Poverty Alleviation Tensor

By tensor join, the three tensor models of poverty-stricken households, assistance measures and poverty alleviation implementation situation are fused. Tensor join is to merge two dimensions with the same tensor and keep other different dimensions. Therefore, the poverty alleviation tensor $\mathrm{T}$ is finally formed.

\subsection{Association Analysis}

The HOSVD of the poverty alleviation tensor $\mathrm{T}$ is carried out,then a core tensor $\mathrm{S}$ and the poverty alleviation factor matrix $\mathrm{U}(\mathrm{i})(1 \leq \mathrm{i} \leq \mathrm{n})$ are obtained.

$$
\mathrm{T}=\mathrm{S} \times{ }_{1} \mathrm{U}^{(1)} \times{ }_{2} \mathrm{U}^{(2)} \ldots \times{ }_{\mathrm{n}} \mathrm{U}^{(\mathrm{n})}
$$

The core tensor $S$ of poverty alleviation represents the importance of each dimension. Factor matrix $U$ (i) is the characteristic of tensor $\mathrm{T}$ in this dimension. It is a left singular matrix obtained by SVD decomposition of tensor T's N-module expansion matrix $\mathrm{T}(\mathrm{n})$ :

$$
\mathrm{T} \mathrm{m} \times n=U \mathrm{~m} \times m A \mathrm{~m} \times n\left(V_{\mathrm{n} \times n)^{\mathrm{T}}}\right.
$$

Where left singular matrix $U$ and right singular matrix $\mathrm{V}$ are orthogonal to each other, and they are characteristic matrices of rows and columns respectively. A is a diagonal singular value matrix.

Truncate the singular value of the threshold factor $\mathrm{K}$ in the core tensor S . After multiplying the truncated core tensor Sk and factor matrix $U$ (i) $(1 \leq \mathrm{i} \leq \mathrm{n})$, the approximate tensor Ts. Ts is a dense approximation of the original poverty tensor $\mathrm{T}$, which has removed noise data and is more conducive to data recommendation.

\subsection{Precision Recommendation}

In the approximate tensor Ts of poverty alleviation,sort the effectiveness of poverty alleviation measures for poor households in each poverty alleviation situation .Finally,we obtain the precise recommended tensor $\mathrm{H}$ of poverty alleviation. By analyzing the dimensions of poor households ,The precise recommendation tensor $\mathrm{H}$ of poverty alleviation can recommend poverty alleviation measures for poor households, and help poor households get out of poverty accurately.

\section{PRACTICE AND APPLICATION}

\subsection{Smart Poverty Alleviation Practice}

Focusing on the smart poverty alleviation architecture based on geomatics big data, the targeted poverty alleviation platform has 
been piloted in Guangxi Tiandeng, China. At present, the platform runs smoothly, monitors and assists timely and efficiently from multiple dimensions such as county, township, village, household and archives.It improves the work efficiency of helping cadres,recommends poverty alleviation policies and accelerates the progress of poverty alleviation. It can improve the efficiency of poverty alleviation archives, shorten the poverty alleviation archives cycle, and improve the poverty alleviation archives storage and access methods. The experiment proved that the smart poverty alleviation architecture based on geomatics big data is feasible and effective.

\subsection{Smart poverty alleviation application}

The targeted poverty alleviation platform includes the targeted poverty alleviation monitoring APP,the targeted poverty alleviation monitoring Browser system and the targeted poverty alleviation archives management information Desktop-client system.

The monitoring APP has functions like attendance input, progress report of poverty alleviation projects, monitoring of poverty-stricken indicators, policy interpretation, etc.It is accurate to the household based on geomatics big data, that is, help cadres must go to poor households' home address to help poors. The screenshot of the APP implementation effect interface is Figure 2.

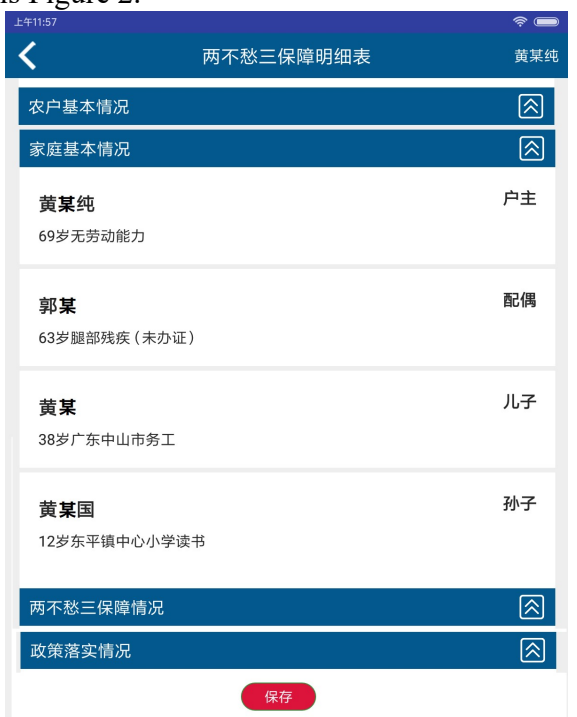

Figure 2. Monitoring APP screenshot

The monitoring Browser system includes poverty alleviation, basic conditions, sign-in management, project management and other functions.It achieves poverty alleviation monitoring and assistance at the county, township,township and village levels based on geomatics big data.It manages the monitoring of poor households in APP. The screenshot of the Browser system implementation effect interface is Figure 3.

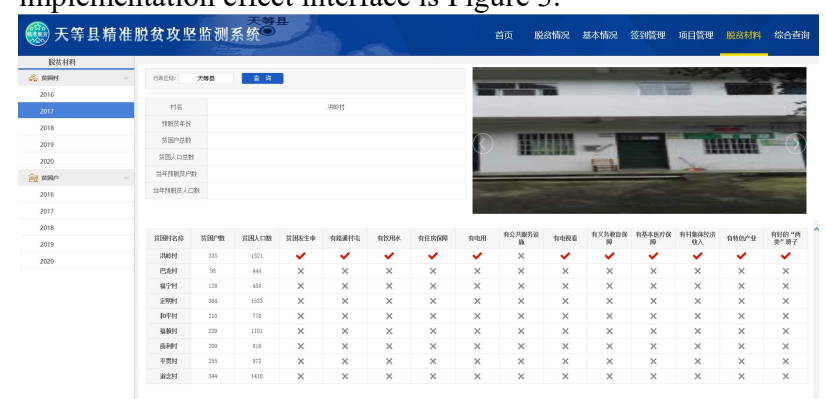

Figure 3. Monitoring Browser system screenshot

The archives management information Desktop-client system has functions such as archives browse and query, data management, configuration management, and map navigation. It can visually manage, query, display, and analysis accurate recommendations for poverty alleviation. The screenshot of the Desktop-client system implementation effect interface is Figure 4.

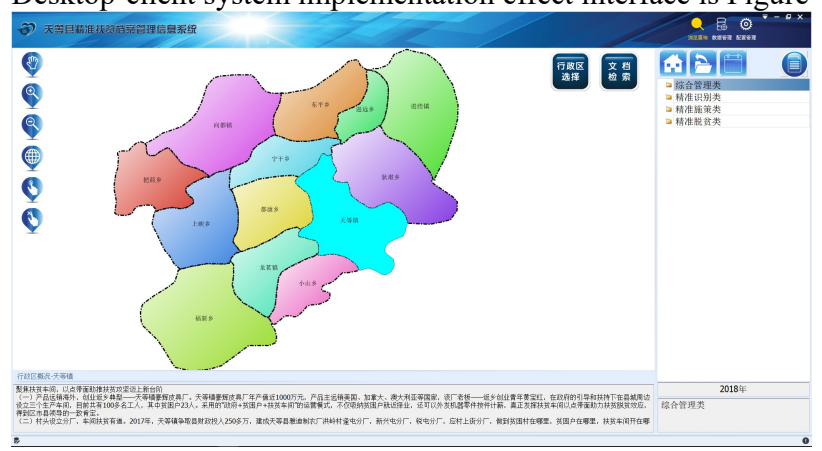

Figure 4. Archives Desktop-client system screenshot

\section{CONCLUSIONS}

In summary, the research on smart poverty alleviation architecture based on geomatics big data closely combines with China's policy requirements of resolutely winning the fight against poverty.It is oriented to the needs and applications of poverty alleviation monitoring and poverty alleviation archives.It is based on the innovation of smart service model based on geomatics and big data.It carries out the display,the multiterminal collaborative monitoring and the accurate recommendation for poverty alleviation.It effectively recommends poverty alleviation assistance policies, improves the efficiency of poverty alleviation archives collation, shortens the period of poverty alleviation archives collation, and improves the storage and access methods of poverty alleviation archives. It improves the efficiency of poverty alleviation collection, monitoring and assistance.

In our future work, we plan to expand the scope of geomatics big data, research recommending poverty alleviation industry and mining characteristic industries in poor mountainous areas based on satellite imagery,help China to complete the process of building a moderately well-off society in all aspects.

\section{REFERENCES}

Ruiqiang Zheng,Guoqing Cao,2015:Research on Precision Poverty Alleviation Mechanism Based on Big Data Thinking.Guizhou Social Sciences, 2015(8):163-168.

Guanghui Mo,2016.The application and practice innovation of big data in the process of precision poverty alleviation.Truth Seeking,2016(10):87-96.

Xu Zhao,2017.Research on Precise Poverty Alleviation Mode Based on Big Data Thinking.Proceedings of 2017 3rd International Conference on Humanities and Social Science Research(ICHSSR 2017),2017:4.

Changping Zhang,Tao Lin,2017."Habitat” Simulation: Big Data Association Integration and Precision Poverty Alleviation Centered on the Poor Population.Journal of Public Management, 14(03):124-134+153+159.

Wolfgang Hackbusch,André Uschmajew,2017.On the interconnection between the higher-order singular values of real tensors.Numerische Mathematik,135(3):1-20. 